\title{
The Biosynthesis of Phenols
}

\section{THE RELATIONSHIPS OF SOME PHENOLIC METABOLITES OF MUTANTS OF ASPERGILLUS TERREUS THOM, I.M.I. 16043*}

\author{
By R. F. CURTIS, P. C. HARRIES, C. H. HASSALL AND J. D. LEVI \\ Department of Chemistry, University College of Swansea, Singleton Park, Swansea
}

(Received 7 May 1963)

Suggestions for the stages in the biosynthesis of phenolic compounds from acetate and malonate units have been based largely on the comparison of structures of naturally occurring phenols and on labelling experiments with radioactive isotopes (Birch, 1962). Although these studies have been very fruitful, they have not made it possible to differentiate some alternative pathways of biosynthesis of relatively complex phenolic compounds. For example, there is little evidence on the sequence of steps in the biosynthesis of such compounds as tetracyclines (Miller, 1961), hydroxyanthraquinones (Gatenbeck, 1960) and polyhydroxybenzophenones.

It seemed possible that the use of mutants of the fungi that produced such compounds might provide information on their mode of biosynthesis. Auxotrophic mutants of micro-organisms have been used extensively for the elucidation of the biosynthesis of compounds such as amino acids (Davis, 1955), vitamins (Tatum \& Bell, 1946), purines (Giles, Partridge \& Nelson, 1957) and others that are essential for normal metabolism. There is, however, little information on the use of mutants of fungi for investigations on the biosynthesis of compounds that do not appear to have an 'essential' function. Nevertheless, there is some precedent for such work in studies on the biosynthesis of flavonoids in plants (Geissman, 1962). Investigations with colour mutants of the cultivated plant Primula sinensis (Harborne \& Sherratt, 1961), the diploid potato Solanum phureja (Harborne, 1960), and others, have contributed important information on the course of such processes as hydroxylation, methylation and glycosidation in the biosynthesis of flavonoids.

In the present study we utilized a strain of Aspergillus terreus Thom, I.M.I. 16043, that produces the chlorinated polyphenol geodoxin (VIII) (Hassall \& McMorris, 1959). Colonies from spores surviving irradiation with ultraviolet light have been examined to distinguish differences in phenol biosynthesis and to determine whether it was possible to elucidate the biosynthesis of geodoxin and related compounds.

\footnotetext{
* Part 4: Hassall \& Jones (1962).
}

\section{EXPERIMENTAL}

Ultraviolet-absorption spectra were measured in ethanol with a Unicam SP. 500 or an Optica CF 4 recording spectrophotometer. Infrared-absorption spectra were measured in potassium bromide disks with a Perkin-Elmer Infracord spectrometer. Melting points were measured on a Kofler block and are uncorrected. Isotopically labelled compounds were purchased from The Radiochemical Centre, Amersham, Bucks.

\section{Chromatographic methods}

Silica gel for chromatography (British Drug Houses Ltd., Poole, Dorset) was washed with dilute acetic acid (5\%, $\mathrm{v} / \mathrm{v}$ ) and then methanol, and dried at $90^{\circ} / 15 \mathrm{~mm}$. $\mathrm{Hg}$ for $4 \mathrm{hr}$. Cellulose powder for chromatography (Whatman no. 1 'Ashless') was prepared by washing with ethylenediaminetetra-acetic acid $(3 \%, \mathrm{w} / \mathrm{v})$ for $2 \mathrm{hr}$. After filtration the powder was washed with deionized water for $24 \mathrm{hr}$. and dried at $90^{\circ} / 5 \mathrm{~mm}$. Hg for 2 days.

Paper chromatograms. The following systems were used for the identification of the phenolic components. Descending chromatograms were run at $20 \pm 0.5^{\circ}$ on Whatman no. 1 paper. System I: benzene-cyclohexane-methanolwater $(5: 5: 6: 4$, by vol.), and, after equilibration overnight, $0.5 \%(\mathrm{v} / \mathrm{v})$ of acetic acid was added to the upper layer (Rhodes, Boothroyd, McGonagle \& Somerfield, 1961). System II: benzene-acetic acid-water $(20: 5: 4$, by vol.). System III: ethyl methyl ketone-water-diethylamine (921: 77:2, by vol.) (Reio, 1958).

Thin-layer chromatograms. For chromatograms on Kieselgel G (Merck, Darmstadt) $(20 \mathrm{~cm} . \times 20 \mathrm{~cm}$. plates), the solvent system benzene-methanol-acetic acid (10:2:1, by vol.) was used. Plates were activated before use for $1 \mathrm{hr}$. at $120^{\circ}$ and equilibrated for $1 \mathrm{hr}$. before development. Chromatographic reagents. All chromatograms were dried and then examined under ultraviolet illumination

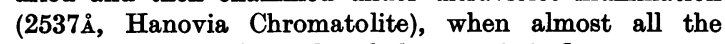
phenolic compounds produced characteristic fluorescent or absorbent spots. After this examination chromatograms were sprayed with a freshly prepared solution of a stabilized diazonium salt of $o$-dianisidine (L. Light and Co. Ltd., Colnbrook, Bucks.) $(0.05 \mathrm{~g}$.) in $40 \mathrm{ml}$. of methanol-water (1:1, $\mathrm{v} / \mathrm{v}$ ), followed by methanol-aq. ammonia (sp.gr. 0.88) $(1: 1, v / v)$ to promote the coupling reaction. Paper chromatograms could be sprayed immediately after development but thin-layer chromatograms gave improved colour resolution if allowed to dry overnight before spraying.

On thin-layer chromatograms sprayed with the diazonium reagent, sulochrin, dechlorogeodin or asterric acid could be detected at concentrations of $0.2 \mu \mathrm{g}$.; under ultra- 
violet illumination the minimum visible concentrations were: sulochrin, $1 \mu \mathrm{g}$.; dechlorogeodin, $2.5 \mu \mathrm{g}$.; asterric acid, $0 \cdot 2 \mu \mathrm{g}$.

\section{Microbiological methods}

Organism. A. terreus Thom, I.M.I. 16043 was used as the wild-type. All the mutants described below were derived from this strain. Stock cultures were maintained on complete agar and subcultured at intervals of about 4 weeks. All cultures were stored at $4^{\circ}$.

Solid media. (a) Czapek-Dox agar. This contained glucose monohydrate (40 g./1.) and $\mathrm{NaNO}_{3}(3 \cdot 3 \mathrm{~g} . / 1$.), and was used as the minimal solid medium.

(b) Complete medium. This contained sucrose (30 g.), corn-steep liquor (10 g.) (Boots Pure Drug Co. Ltd., Nottingham), Difco yeast extract (3 g.), $\mathrm{KH}_{2} \mathrm{PO}_{4}$ (1 g.), $\mathrm{MgSO}_{4}, 7 \mathrm{H}_{2} \mathrm{O}\left(0.5 \mathrm{~g}\right.$.), $\mathrm{KCl}(0.5$ g. $), \mathrm{FeSO}_{4}, 7 \mathrm{H}_{2} \mathrm{O}$ (0.01 g.), methionine $(0.05 \mathrm{~g}$.), nucleic acids solution $(3 \mathrm{ml}$.), groundnut oil $(1 \mathrm{ml}$.) and agar $(20 \mathrm{~g}$.$) , together made up to 1 \mathrm{l}$. with tap water and adjusted with $0 \cdot 1 \mathrm{~N}$-sodium hydroxide to give pH 7·0. The sucrose was sterilized separately. The solution of nucleic acids was prepared by separately boiling portions (2 g.) of yeast ribonucleic acid (British Drug Houses Ltd.) with $\mathrm{N}$-sodium hydroxide $(15 \mathrm{ml}$.$) and$ $\mathrm{N}$-hydrochloric acid $(15 \mathrm{ml}$.), mixing the solutions, adjusting to $\mathrm{pH} \mathrm{6}$, filtering, making up to $40 \mathrm{ml}$. and storing in the dark over a layer of chloroform.
Liquid media. (a) Seed medium. This contained sucrose (70 g.), corn-steep liquor (23 g.), $\mathrm{CaCO}_{3}\left(8 \mathrm{~g}\right.$.), $\mathrm{K}_{2} \mathrm{HPO}_{4}$ (4 g.) and $\mathrm{KCl}(2 \mathrm{~g}$.), together made up to 1 l. with tap water to give a final $\mathrm{pH} 6 \cdot 7$, without adjustment.

(b) Shaken-flask and fermenter medium. This contained sucrose (40 g.), corn-steep liquor (20 g.) and $\mathrm{K}_{2} \mathrm{HPO}_{4}(4 \mathrm{~g}$.), together made up to 1 l. with tap water to give a final pH 5.5-6.0, without adjustment.

(c) Modified Czapek-Dox medium. This contained glucose monohydrate (40 g.), urea (1.2 g.), $\mathrm{K}_{2} \mathrm{HPO}_{4}$ $\left(0.6\right.$ g.), $\mathrm{KH}_{2} \mathrm{PO}_{4} \quad\left(0.4\right.$ g.), $\mathrm{MgSO}_{4}, 7 \mathrm{H}_{2} \mathrm{O} \quad(0.5 \mathrm{~g}$.), $\mathrm{KCl}$ $\left(0.5\right.$ g.) and $\mathrm{FeSO}_{4}, 7 \mathrm{H}_{2} \mathrm{O}(0.01 \mathrm{~g}$.), together made up to $1 \mathrm{l}$. with tap water to give a final $\mathrm{pH} 6 \cdot 6-6 \cdot 8$, without adjustment.

(d) Chloride-free medium. This was formulated as for the modified Czapek-Dox medium except that $\mathrm{KCl}$ was omitted. AnalaR reagents in distilled water were used and glucose was freed from $\mathrm{Cl}^{-}$ion by using silver nitrate solution and removing excess of $\mathrm{Ag}^{+}$ion by precipitation with hydrogen sulphide.

Culture conditions. Experiments with stationary-phase cultures required relatively long periods of growth and were not always reproducible. The experiments described below all involved either shaken-flask or submerged aerated cultures. Incubation was at $25^{\circ}$ throughout.

Shaken-flask cultures. These were carried out with portions $(60 \mathrm{ml}$.$) of medium in 250 \mathrm{ml}$. conical flasks,

Table 1. $R_{F}$ values of phenolic metabolites of Aspergillus terreus and related compounds

Experimental details, including descriptions of systems I-IV, are given in the text; system IV represents thin-layer chromatography. (fl), Fluorescent spot; (q), quenched spot.

\section{Compound}

Asterric acid (VI)

Asterric dicarboxylic acid*

Citrinin (XVI) $\dagger$

Dechlorogeodin (III)

Dechlorogeodoxin $\ddagger$

Dichloro-orcinol

Dichloro-p-orsellinic acid

Dihydroerdin§

Dihydrogeodin (II)

3,5-Dihydroxy-1,2-dimethylbenzene

2,4-Dihydroxy-1,3-dimethylbenzene

1,3-Dihydroxy-2,5-dimethylbenzene

4,6-Dihydroxy-2,3-dimethylbenzoic acid (XIV)

3,5-Dihydroxyphthalic acid (IX)

Erdin (V)

Erdin hydrate§

Gentisic acid

Geodin (IV)

Geodin hydrate (VII)

Geodoxin (VIII)

Griseofulvin|

2-Hydroxy-6-methylbenzoic acid (X)

5-Hydroxy-3-methoxyphthalic acid

Orcinol monomethyl ether

Orcinol (XII)

$o$-Orsellinic acid (XIII)

$p$-Orsellinic acid

Sulochrin (I)

* Curtis, Hassall, Jones \& Williams (1960).

$\ddagger$ Hassall \& Lowis (1961).

I| Grove, MacMillan, Mulholland \& Rogers (1952).

** Colour on thin-layer chromatograms.

\begin{tabular}{|c|c|c|c|c|}
\hline \multirow[b]{2}{*}{ System... } & \multicolumn{4}{|c|}{$R_{F} \times 100$} \\
\hline & I & II & III & IV \\
\hline & 44 & 75 & 40 & 55 \\
\hline & 0 & 0 & 3 & 30 \\
\hline & 15 & 90 & 60 & 42 \\
\hline & 62 & 88 & 65 & 61 \\
\hline & 95 & 97 & 80 & 55 \\
\hline & 37 & 55 & 80 & 60 \\
\hline & 10 & 30 & 80 & 15 \\
\hline & 0 & 20 & 40 & 35 \\
\hline & 60 & 75 & 89 & 52 \\
\hline & 3 & 13 & 95 & 40 \\
\hline & 20 & 33 & 95 & 49 \\
\hline & 10 & 22 & 95 & 45 \\
\hline $\mathrm{d}(\mathrm{XIV})$ & $0-5$ & 25 & 38 & 47 \\
\hline & 0 & 0 & $\mathbf{5}$ & 5 \\
\hline & 80 & 43 & 13 & 38 \\
\hline & 95 & 5 & 18 & 9 \\
\hline & 0 & 5 & 25 & 32 \\
\hline & 92 & 92 & 86 & 75 \\
\hline & 10 & 90 & 80 & 33 \\
\hline & 95 & 97 & 87 & 85 \\
\hline & 90 & 93 & 90 & 64 \\
\hline & 60 & 75 & 54 & 65 \\
\hline & 0 & 0 & 0 & 12 \\
\hline & 0 & 80 & 90 & 63 \\
\hline & 0 & $\mathbf{5}$ & 90 & 39 \\
\hline & 0 & 10 & 30 & 43 \\
\hline & 0 & 12 & 75 & 25 \\
\hline & 0 & 10 & 90 & 40 \\
\hline
\end{tabular}

Colour under ultraviolet irradiation

Turquoise (fl)

Blue (fl)

Yellow-green (fl)

Purple (q)

Purple (q)

Purple (q)

Purple (q)

Purple (q)

Purple (q)

Purple (q)

Purple (q)

Purple (q)

Mauve (fl)

Blue (fl)

Dark grey (q)

Blue (fl)

Blue (fl)

Dark grey (q)

Blue (fl)

Dark purple (q)

Blue (fl)

Mauve (fl)

Purple (fl)

Purple (q)

Purple (q)

Mauve (fl)

Mauve (fl)

Purple (q)
Colour with diazonium reagent

Magenta

Magenta

Pale pink

Magenta

Magenta

Red-brown

Deep pink

Magenta

Purple (orange)**

Magenta

Magenta

Purple-red

Magenta

Magenta

Dark yellow

Magenta

Pale brown

Pale yellow

Magenta

Pale orange

Pale yellow

Purple

Magenta

Magenta

Magenta

Purple-red

Bright red $\dagger$ Birch et al. (1958).

$\S$ Calam, Clutterbuck, Oxford \& Raistrick (1947).

ๆ Barton \& Scott (1958). 
sterilized by autoclaving for $20 \mathrm{~min}$. at $15 \mathrm{lb}$./in. ${ }^{2}$. The rotary shaker operated at $200 \mathrm{rev} . / \mathrm{min}$. with a throw of $5 \mathrm{~cm}$. An inoculum for shaken-flask-culture screening experiments consisted of a spore suspension prepared in sterile water from mature culture slopes, so as to contain $10^{6}-10^{7}$ spores or mycelial fragments/ml. This suspension (1 ml.) was used to inoculate each flask. Alternatively, portions (1-5 ml.) from 48-hr. shaken-flask cultures on seed medium were used.

In developing media, the sodium nitrate in normal Czapek-Dox medium was replaced by alternative sources of nitrogen. Ammonium nitrate, asparagine, ammonium tartrate and urea gave increased yields of geodin. Spore germination was most favourable with urea, and this led to a decrease of pellet formation. It was found that the optimum carbon:nitrogen ratio was $60: 1$ when urea was used as the source of nitrogen. The addition of $p$-aminobenzoic acid, biotin, inositol, nicotinamide, calcium $d$ pantothenate, pyridoxine hydrochloride, riboflavin, thiamin, acid-hydrolysed casein or trace amounts of $\mathrm{Ca}^{2+}$, $\mathrm{Cu}^{2+}, \mathrm{Fe}^{3+}, \mathrm{Mg}^{2+}, \mathrm{Mn}^{3+}$ or $\mathrm{Zn}^{2+}$ ions did not increase the yields of phenolic compounds.

The modified Czapek-Dox medium and the standard shaken-flask medium yielded similar phenolic compounds. The latter medium was usually employed for routine screening since it generally produced larger yields of phenolic compounds. The usual incubation period for shaken-flask cultures was 6 days but certain mutants were sampled daily up to a total of 9 days.

Aerated submerged culture in fermenters. Fermenters (model F-07; New Brunswick Scientific Co., New Brunswick, N.J., U.S.A.) were operated at a working volume of 5 l. of medium. Ancillary equipment provided sterile air, agitation, temperature control, inoculation, anti-foam addition and sampling facilities. Fermenters were sterilized by autoclaving for $45 \mathrm{~min}$. at $15 \mathrm{lb}$./in.2. The seed-medium inoculum (with seeds grown for $48 \mathrm{hr}$.) was $300 \mathrm{ml}$. and aeration was $0.5 \mathrm{vol} . / \mathrm{vol} . / \mathrm{min}$. Agitation was at $200 \mathrm{rev} . /$ min. and fermentations were carried out for periods of up to 6 days.

Larger-scale fermentations (25 l.) were carried out in a modified Hoover washing machine based on a design kindly provided by Imperial Chemical Industries Ltd. The results were similar to those obtained with $5 \mathrm{l}$. fermenters.

\section{Mutation studies}

Ultraviolet light (2537 $\AA$, Hanovia Chromatolite) was used as a mutagen (Hollaender, Raper \& Coghill, 1945; Arpai, 1959). The working distance was $30 \mathrm{~cm}$., in an irradiation box designed to contain eight $9 \mathrm{~cm}$. Petri dishes.

For the isolation of morphological mutants spores were spread on plates of complete medium agar and irradiated. For auxotrophic mutants a spore suspension in sterile water $(10 \mathrm{ml}$.) in a Petri dish was irradiated with intermittent agitation, and portions were treated as described below.

Irradiation time varied from 5 min. (about $60 \%$ survival) to $16 \mathrm{~min}$. (about $1 \%$ survival). A graph of $\log$ (survivors) against time of ultraviolet irradiation gave a straight line, indicating that first-order kinetics were involved.

Selection of mutants. (a) Morphological mutants. These survivors from ultraviolet irradiation differed in colony form or colour from wild-type. In general, they remained stable in subculture over periods up to 2 years and are therefore described as mutants.

(b) Auxotrophic mutants. All morphological mutants were tested for growth-factor requirements. In addition, spore suspensions were irradiated as described above and a filtration enrichment technique (Fries, 1947) was used. The filtrate from this treatment was plated on complete medium and replicated to Czapek-Dox medium to identify auxotrophs. These were isolated and then the growth-factor requirements were characterized by the auxanographic technique (Beijerinck, 1889). Selected strains with single growth-factor requirements were irradiated further to obtain cultures with double requirements.

(c) Normal morphology survivors. These were selected at random from plates containing survivors of ultravioletirradiation treatment and were indistinguishable from wildtype on inspection.

Screening of mutants. Differences in the nature of the phenolic metabolites of morphological and auxotrophic mutants were determined by paper chromatography. Broths $(60 \mathrm{ml}$.) from 6-day shaken-flask cultures were macerated in a Waring Blendor. A portion (15 ml.) was extracted with ethyl acetate $(12 \mathrm{ml}$.) for $30 \mathrm{~min}$. in a liquidliquid extractor. The extract was evaporated under reduced pressure. The residue was dissolved in acetone $(1 \mathrm{ml}$.) and a portion (0.05 ml.) used for paper chromatography.

Mutants that gave the same chromatographic pattern as wild-type were discarded. The remaining mutants were examined further in 'time-growth' experiments. This involved examination, by paper and thin-layer chromatography, of extracts obtained from a set of replicate flask cultures which were harvested daily over a period of 9 days. In these experiments ether $(60 \mathrm{ml} . / 60 \mathrm{ml}$. of broth) was used for extractions in addition to ethyl acetate.

\section{Identification of phenolic metabolites}

Chlorinated compounds. The chlorinated compounds given in Table 1 were isolated according to procedures that have already been described (Calam, Clutterbuck, Oxford \& Raistrick, 1947; Hassall \& McMorris, 1959). They were identified in culture fluids by paper and thin-layer chromatography with the systems mentioned above. The absence of chlorinated metabolites in cultures of particular mutants was confirmed by radioautography with ${ }^{36} \mathrm{Cl}(1 \mu \mathrm{C}$ as $\mathrm{H}^{36} \mathrm{Cl}$ ), which was added to sterile shaken-flask cultures $(60 \mathrm{ml}$.) before inoculation. After growth, harvesting and extraction, the paper chromatograms obtained in the usual way were exposed to X-ray film (No-Screen; Ilford Ltd.) for 7-14 days. Under these conditions wild-type cultures gave radioautographs in which the spots were in the same positions as those of chlorinated metabolites on paper chromatograms sprayed with $o$-dianisidine reagent.

Non-chlorinated compounds. The phenols produced by various mutants were all characterized after isolation from culture fluids. They were identified by further screening, on paper and thin-layer chromatograms. The isolation and identification of the three following compounds from culture fluids has not been described in previous studies.

(i) 2-Hydroxy-6-methylbenzoic acid (X). A submerged culture $(2.75$ l.) of the mutant no. 208 was harvested after 3 days, adjusted to $\mathrm{pH} 3.8$ with $2 \mathrm{~N}$-hydrochloric acid and shaken with ether $(5 \times 400 \mathrm{ml}$.). The organic layer was washed with water, dried (over $\mathrm{MgSO}_{4}$ ) and reduced in volume to $200 \mathrm{ml}$. Examination of a portion showed that 
this extract contained a crude mixture (1.99 g.), and paper chromatography (system II; $o$-dianisidine spray) indicated the presence of three phenolic compounds with $R_{F}$ values of $0 \cdot 1,0.25$ and 0.75 . The presence of further compounds (probably non-phenolic) with $R_{F} \mathbf{0 . 8}$ (brown spot) and $R_{F} 0.9$ (bright-green fluorescence) was indicated by ultraviolet illumination, but these metabolites were not further investigated.

The ether extract was further extracted by shaking with saturated potassium hydrogen carbonate $(3 \times 20 \mathrm{ml}$. $)$, which removed the three phenolic compounds. The alkaline solution was acidified, shaken with ether $(3 \times 100 \mathrm{ml}$.), and the brown gum (530 mg.) obtained by evaporating the ether was chromatographed on a column $(5 \mathrm{~cm} . \times 2.5 \mathrm{~cm}$.) of silica gel with benzene-acetic acid $(99: 1, v / v)$. The eluate (11.) gave a light-brown gum (385 mg.) which was chromatographed on a column $(55 \mathrm{~cm} . \times 2.5 \mathrm{~cm}$.) of powdered cellulose with benzene-acetic acid-water (upper phase; $4: 1: 2, \nabla / v)$. Three major fractions were eluted in turn. The ether extract of each fraction was evaporated below $30^{\circ}$ under reduced pressure, and residual acetic acid was removed over sodium hydroxide.

The first fraction (86 mg.) contained two compounds $\left(R_{F}\right.$ values 0.75 and 0.8$)$. The crude material was sublimed $(115 \%$ /0.05 mm. Hg) to give a pale-yellow product (35.7 mg.) which was chromatographed twice on a column $(45 \mathrm{~cm} . \times$ $1.5 \mathrm{~cm}$.) of powdered cellulose. This column had been equilibrated for $24 \mathrm{hr}$. with the solvent mixture used in system I and elution was carried out with the same solvent. Evaporation of the early fractions gave a product (9 mg.), which was crystallized from light petroleum (b.p. $60-80^{\circ}$ ) to give 2-hydroxy-6-methylbenzoic acid (X), m.p. $169^{\circ}$, unchanged by admixture with an authentic sample, m.p. $168^{\circ}$, kindly supplied by Imperial Chemical Industries Ltd. (Dyestuffs Division) (Found: C, 63.2; H, 5.3. Calc. for $\mathrm{C}_{8} \mathrm{H}_{8} \mathrm{O}_{3}: \mathrm{C}, 63 \cdot 2 ; \mathrm{H}, 5 \cdot 3 \%$ ). The infrared-absorption spectrum and paper chromatograms in systems I, II and III of the natural product were identical with those of the authentic sample.

Evaporation of the later fractions gave another product (7 mg.), corresponding to the compound with $R_{F} 0 \cdot 8$, in the original extract. It crystallized from light petroleum (b.p. $60-80^{\circ}$ ) as needles, m.p. 123-124. This compound gave a transient pink coloration with ethanolic ferric chloride and is being further investigated.

(ii) 4,6-Dihydroxy-2,3-dimethylbenzoic acid (XIV). The second fraction from the above isolation procedure consisted of a brown gum (36 mg.) containing a single phenolic component with $R_{F} \mathbf{0 \cdot 2 5}$. The gum was crystallized twice from benzene-light petroleum (b.p. $60-80^{\circ}$ ), triturated with hot chloroform, sublimed $\left(135^{\circ} / 0.08 \mathrm{~mm} . \mathrm{Hg}\right)$ and finally crystallized from ethyl acetate-light petroleum (b.p. 60 $80^{\circ}$ ) to give 4,6-dihydroxy-2,3-dimethylbenzoic acid (XIV) $\left(7.5 \mathrm{mg}\right.$.) as thin needles, m.p. $159-162^{\circ}$ (decomp.), $\lambda_{\max }$ 263 and $306 \mathrm{~m} \mu$ ( $\epsilon 12020$ and 5180); the mixed m.p. with an authentic sample (m.p. $162-163^{\circ}$ ), prepared according to the method of Robertson \& Whalley (1949), was $162-163^{\circ}$ (Found: C, 59.6; H, 5.8. Calc. for $\mathrm{C}_{9} \mathrm{H}_{10} \mathrm{O}_{4}$ : C, 59.3; $\mathrm{H}, 5.5 \%$ ). The infrared-absorption spectrum showed a band at $1630 \mathrm{~cm} .^{-1}(\mathrm{OH}$ bonded $\mathrm{CO})$ (cf. o-orsellinic acid, $1634 \mathrm{~cm}^{-1} ; p$-orsellinic acid, $1678 \mathrm{~cm}^{-1}$ ) and was identical with that obtained from authentic material. The compounds showed identical $R_{F}$ values in systems I, II and III.
A portion (16 mg.) of the 4,6-dihydroxy-2,3-dimethylbenzoic acid was dissolved in $2 \mathrm{~N}$-sodium hydroxide $(2 \mathrm{ml}$.) and boiled in an atmosphere of nitrogen for $20 \mathrm{~min}$. The product was acidified, extracted with ether and worked up in the usual way to give a gum which was sublimed $\left(130^{\circ} / 0.05 \mathrm{~mm} . \mathrm{Hg}\right)$ and crystallized from chloroform-light petroleum (b.p. $60-80^{\circ}$ ) to give 3,5-dihydroxy-1,2-dimethylbenzene (2.5 mg.), as rhombs, m.p. $135-136^{\circ}, \lambda_{\max } 282 \mathrm{~m} \mu$ $(\epsilon 2250)$. The mixed m.p. with an authentic sample (m.p. $136^{\circ}$ ), prepared according to the method of Strating \& Backer (1943), was $136^{\circ}$ (Found: $\mathrm{C}, 69 \cdot 7 ; \mathrm{H}, 7 \cdot 2$. Calc. for $\mathrm{C}_{8} \mathrm{H}_{10} \mathrm{O}_{2}: \mathrm{C}, 69.5 ; \mathrm{H}, 7 \cdot 3 \%$ ). The infrared-absorption spectrum and paper chromatograms in systems I, II and III were identical with those of authentic material.

Paper chromatography studies showed that all three phenolic compounds isolated from mutant no. 208 were regularly present in the culture fluids of other mutants. When $\left[M e^{-14} \mathrm{C}\right]$ methionine $(16 \mu \mathrm{c})$ was added to a shakenflask culture $(60 \mathrm{ml}$.) of the wild-type, paper chromatograms of the extract gave radioautographs in which the most intensely defined spot corresponded to 4,6-dihydroxy2,3-dimethylbenzoic acid (XIV).

(iii) $o$-Orsellinic acid (XIII). The third fraction from the culture fluid of mutant no. 208 contained only one phenolic compound, with $R_{F} 0 \cdot 1$. Evaporation of the ether extract under reduced pressure gave brown crystalline material (25 mg.). This was chromatographed on a column $(45 \mathrm{~cm} . \times 1.5 \mathrm{~cm}$.) of cellulose powder that had been equilibrated for $48 \mathrm{hr}$. with the solvent mixture used in system II. The column was eluted with the same solvent and the later fractions were crystallized from water to give 0 -orsellinic acid (9 mg.), m.p. $176^{\circ}$. The mixed m.p. with an authentic sample (m.p. $177^{\circ}$ ), prepared according to the method of Hoesch (1913), was 176-177 (Found: C, 57.1; H, 4.9. Calc. for $\mathrm{C}_{8} \mathrm{H}_{8} \mathrm{O}_{4}: \mathrm{C}, 57 \cdot 1 ; \mathrm{H}, 4 \cdot 8 \%$ ). The infrared-absorption spectrum and the behaviour on paper chromatography in systems I, II and III were identical with those of authentic material.

(iv) Sulochrin (I). Sulochrin was identified in wildtype cultures of $A$. terreus and in cultures of various mutants by paper chromatography in system III and thinlayer chromatograms. In a typical isolation (carried out in collaboration with Mr D. M. Phillips in this Laboratory), a submerged culture $(480 \mathrm{ml}$.) of wild-type $A$. terreus in chloride-free medium was collected after $96 \mathrm{hr}$. The mycelium was removed by filtration and the filtrate extracted with ether $(8 \times 60 \mathrm{ml}$. $)$ which was dried and distilled. The residue crystallized from ethyl acetate-light petroleum (b.p. $\left.60-80^{\circ}\right)$ to give sulochrin (I) (25 mg.), m.p. 262 . The mixed m.p. with authentic material (m.p. 262 ${ }^{\circ}$ ), isolated from Oospora sulphurea-ochracea (Nishikawa, 1939), was $262^{\circ}$ (Found: C, 61.4; H, 5.1. Calc. for $\mathrm{C}_{17} \mathrm{H}_{16} \mathrm{O}_{7}$ : C, 61.4; H, $4.9 \%$ ).

\section{RESULTS}

Mutation experiments. When an aqueous spore suspension of $A$. terreus was irradiated with ultraviolet light so that there was 90-99\% mortality, approx. $3 \%$ of the survivors were isolated as variants which differed in the appearance of the colonies from the wild-type. These strains gave rise to small, fluffy or raised colonies and there was variation in colour from white to dark brown. As 
there was no reason to connect differences in phenol biosynthesis with variation in morphology or colour, survivors similar in appearance to the wildtype were also utilized. Colonies that grew slowly or failed to grow on minimal medium were treated as potential auxotrophic mutants and were subsequently screened for specific growth requirements by auxanographic plating techniques.

When extracts of 6-day shaken-flask cultures of the 383 isolated strains from the irradiation experiments were examined by paper chromatography for differences in the composition of phenolic constituents, it was found that the majority resembled the wild-type. However, there were marked variations in the number and nature of the phenols synthesized by some of the mutants. No attempt will be made to tabulate all the results of this stage of the study but some indication of the degree of variation may be obtained by differentiating the strains that no longer produce geodin (IV), a phenol that is synthesized in good yield by the wild-type (Raistrick \& Smith, 1936). Strains with this property that were selected in the initial screening experiments were subcultured and retested in 4-day and 6-day shaken-flask cultures; then there was further testing of cultures at intervals of $24 \mathrm{hr}$. over 9 days. In this way mutants that produced geodin but grew slowly, or that showed instability and acquired the capacity to synthesize geodin after subculturing at least three times, could be excluded. Of the 383 isolated strains that were studied in detail, 281 had different morphological characteristics. Of these 19 failed to produce geodin. Of the 90 isolated strains that were indistinguishable, morphologically, from wild-type, only two did not synthesize geodin. There were 12 auxotrophic mutants obtained directly from wildtype, and of these one did not produce geodin. The 22 strains that were selected by this procedure showed no exceptional tendency to change their characteristics on subculturing. Although it was not practicable accurately to measure the rate of reversion in strains distinguished by different phenol phenotypes alone, this was possible with auxotrophs. The results with seven auxotrophs, two of which differed from the wild-type in their mode of synthesis of phenols, are given in Table 2. The reversion rate of one per million spores, or lower, is comparable with natural mutation rates observed in other cases (Sinnott, Dunn \& Dobzhansky, 1958).

Characteristics of the mutants. The availability of reference compounds, and the use of the paperchromatography systems detailed in the Experimental section (Table 1), made it possible to distinguish differences in the capacity of mutants to synthesize $\mathrm{C}_{17}$ compounds related to geodin. Of the 22 mutants that did not synthesize geodin, seven produced mixtures of phenols that included sulochrin (I). However, none of these compounds contained chlorine; this was indicated by the paperchromatography experiments and confirmed by radioautography of chromatograms of extracts from cultures growing on a medium containing potassium $\left[{ }^{36} \mathrm{Cl}\right]$ chloride. Four of the seven mutents in this group produced a complex mixture of phenols, including asterric acid (VI), bisdechlorogeodin (III) and sulochrin (I), that were the same as those produced when the wild-type was grown on chloride-free medium. Of the remaining three mutants in the group, two produced sulochrin and bisdechlorogeodin but no asterric acid, and one produced sulochrin alone (Table 3).

Table 2. Stability of selected auxotrophic mutants of Aspergillus terreus

Experimental details are given in the text.

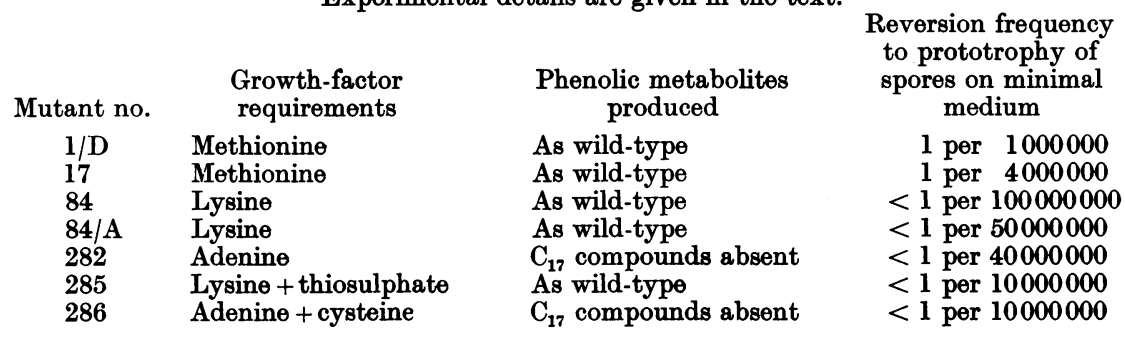

Table 3. $\mathrm{C}_{17}$ metabolites of typical mutants

Experimental details are given in the text.

(a) Non-chlorinated metabolites

$\begin{array}{cccc}\begin{array}{c}\text { Mutant } \\ \text { no. }\end{array} & \text { Sulochrin } & \begin{array}{c}\text { Dechloro- } \\ \text { geodin }\end{array} & \begin{array}{c}\text { Asterric } \\ \text { acid }\end{array} \\ 219 & + & - & - \\ 111 & + & + & - \\ 74 & + & + & +\end{array}$

(b) Chlorinated metabolites

$\begin{array}{ccccc}\begin{array}{c}\text { Mutant } \\ \text { no. }\end{array} & \begin{array}{c}\text { Dihydro- } \\ \text { geodin }\end{array} & \text { Geodin } & \begin{array}{c}\text { Geodin } \\ \text { hydrate }\end{array} & \text { Geodoxin } \\ 258 & + & + & - & - \\ 78 & + & + & + & - \\ \text { Wild-type } & + & + & + & +\end{array}$


Chromatographic examination of the mixture of $\mathrm{C}_{17}$ chlorinated phenols dihydrogeodin (II), geodin (IV), geodin hydrate (VII) (Calam et al. 1947) and geodoxin (VIII) that were produced by different strains led to the identification of one that was unable to synthesize geodoxin but did produce the three related compounds. Other strains produced geodin and dihydrogeodin but no geodin hydrate or geodoxin. No variant has, as yet, been found that produces dihydrogeodin without geodin. The $\mathrm{C}_{17}$ phenols produced by representative mutants are indicated in Table 3. Mutants, other than those listed, that produced combinations of $\mathrm{C}_{17}$ phenols differing from those of the wild-type all resembled one or another of five typical mutants (Table 3) in their capacity to synthesize the $\mathrm{C}_{17}$ compounds.

Of the 22 mutants that did not synthesize geodin, 15 failed to produce sulochrin, dihydrogeodin or any other related $\mathrm{C}_{17}$ phenol. One of these strains (no. 122) produced only three phenolic compounds: o-orsellinic acid (XIII), orcinol (XII) (possibly formed during the extraction process by decarboxylation) and 2-hydroxy-6-methylbenzoic acid (X). Another strain (no. 208) produced the same three phenols together with a compound $\mathrm{C}_{9} \mathrm{H}_{10} \mathrm{O}_{4}$ which gave a red-brown coloration with ferric chloride and had an ultraviolet-absorption spectrum very similar to that of $o$-orsellinic acid. This compound, which has not, as far as we are aware, been isolated before from the culture fluid of a fungus, was identified as 4,6-dihydroxy-2,3-dimethylbenzoic acid (XIV) through decarboxylation to : 3,5-dihydroxy-1,2-dimethylbenzene and comparison with synthetic material. The remaining 13 mutants in this group produced more complex mixtures of phenols. Preliminary studies have indicated that some of the differences were associated with intermediates in the biosynthesis of citrinin (XVI) (Birch et al. 1958; Hassall \& Jones, 1962).

\section{DISCUSSION}

Geodin and erdin were first isolated by Raistrick \& Smith (1936) in their studies on the metabolism of $\mathrm{Cl}^{-}$ion by fungi. This was followed by a series of investigations that resulted in the formulation of the two compounds as (IV) and (V) respectively (Barton \& Scott, 1958). Later work (Hassall \& McMorris, 1959; Curtis, Hassall, Jones \& Williams, 1960) led to the isolation of asterric acid and geodoxin from cultures of strains of $A$. terreus related to those that produced geodin and erdin. The structures (VI) and (VIII) that were assigned to these new compounds were evidently related to that of geodin. This led to the suggestion (Curtis, Hassall \& Jones, 1959) that sulochrin (I), which had not at that time been identified as a constituent of cultures of $A$. terreus, but was a known metabolite of $O$. sulphurea-ochracea (Nishikawa, 1939), might serve as a precursor of geodin in a sequence of biosyntheses leading through 2,4-dichloroasterric acid (VII) to geodoxin. This proposal found support in the observation that each of the stages could be achieved in vitro (Curtis et al. 1959; Hassall \& Lewis, 1961).

Sulochrin has now been isolated from a culture of A. terreus. Moreover, O. sulphurea-ochracea has been shown to produce bisdechlorogeodin, asterric acid and some related derivatives, in addition to sulochrin (Curtis, Hassall, Natori \& Nishikawa,
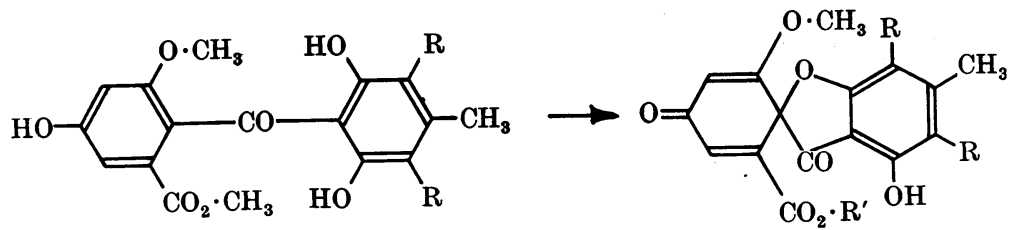

(I), $\mathrm{R}=\mathrm{H}$

(II), $\mathrm{R}=\mathrm{Cl}$

(III), $\mathrm{R}=\mathrm{H} ; \mathrm{R}^{\prime}=\mathrm{CH}_{3}$

(IV), $\mathrm{R}=\mathrm{Cl} ; \mathrm{R}^{\prime}=\mathrm{CH}_{3}$

(V), $\mathrm{R}=\mathrm{Cl} ; \mathrm{R}^{\prime}=\mathrm{H}$

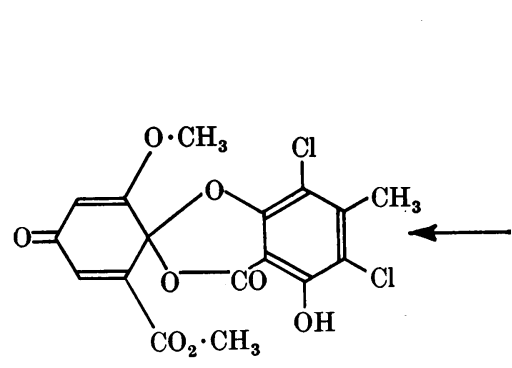

(VIII)

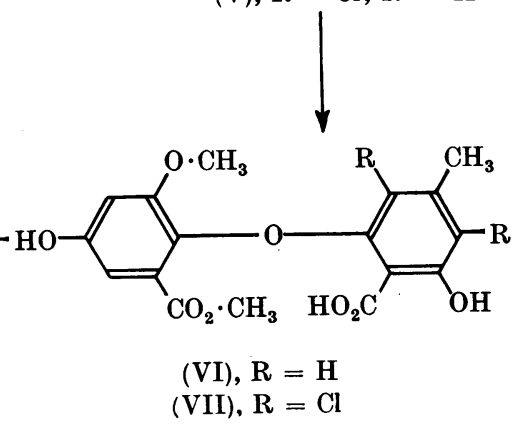

(VI), $\mathrm{R}=\mathrm{H}$ 
1961). Investigations on cultures of Penicillium frequentans (Stickings \& Mahmoodian, 1962) have led to the identification of the three compounds (I), (III) and (VI), together with two anthraquinones that are related in structure. Evidently the sequence of biosynthesis may apply to organisms other than $A$. terreus.

This study provides evidence that the biosynthesis of asterric acid by $A$. terreus proceeds by the stages:

$$
\begin{array}{r}
\text { Sulochrin }(\mathrm{I}) \rightarrow \text { bisdechlorogeodin (III) } \rightarrow \\
\text { asterric acid (VI) }
\end{array}
$$

Mutants that are blocked at each stage in this sequence have been identified (Table 3).

With the corresponding chlorinated compounds, the order of events is not as clearly defined. $P$. frequentans, $O$. sulphurea-ochracea and a mutant of $A$. terreus (no. 74), all growing on a medium containing $\mathrm{Cl}^{-}$ion, produce the same $\mathrm{C}_{17}$ phenols as those that have been identified in cultures of the wild-type of $A$. terreus growing on a medium free from $\mathrm{Cl}^{-}$ion. Moreover, mutants with blocks between the last two stages leading to geodoxin have been obtained (Table 3). The failure to identify a mutant capable of synthesizing dihydrogeodin (II), but not geodin, could be said to favour the argument that geodin is formed by chlorination of bisdechlorogeodin rather than through oxidation of dihydrogeodin. Studies on the order of production of the $C_{17}$ metabolites in shaken-flask cultures have been regarded as providing supporting evidence for the former process (Rhodes, McGonagle \& Somerfield, 1962). However, the interpretation of such results is difficult, particularly as an undefined number of steps is reversible. It has been shown, in support of the second alternative, that enzyme preparations from Penicillium paxilli var. echinulatum can achieve the conversion of dihydrogeodin into geodin (Komatsu, 1957). The evidence obtained in the present work does not define the stage or stages at which chlorination occurs, presumably through the action of a chlorinating enzyme similar to that which has been described in studies on caldariomycin (Shaw \& Hager, 1961), but it does indicate the steps by which geodin is converted into geodoxin.

There have been various speculations on the biosynthesis of sulochrin and similar benzophenone derivatives. Gatenbeck (1960) has proposed that sulochrin might be produced by the oxidation of emodin (XVII) derived from polyacetate precursors. Tatum (1944) and Raistrick (1950) have, on the other hand, suggested that anthraquinones are formed from related benzophenones, e.g. (XI) which might be produced through condensation of two phenols such as (IX) and (X).

It is to be expected that consideration of the metabolites of mutants could contribute to the definition of the course of.biosynthesis of sulochrin.<smiles>Cc1cc(O)c2c(c1)C(=O)c1cc(O)c(C)c(C(=O)O)c1C2=O</smiles>

(X)<smiles>Cc1cc(O)cc(O)c1</smiles> 
Mutants that do not produce sulochrin have been isolated in the present study but, as yet, the phenolic metabolites of only two of these strains have been examined in detail. The most completely blocked mutant (no. 122) produced only three phenolic compounds: orcinol (XII), o-orsellinic acid (XIII) and 2-hydroxy-6-methylbenzoic acid (X). The same compounds, together with 4,6dihydroxy-2,3-dimethylbenzoic acid (XIV), are produced by another mutant (no. 208) and are also found in 48-hr. shaken-flask cultures of the wildtype; no sulochrin has been formed at this stage of the fermentation.

It seemed likely that compound (XIV) was formed by $C$-methylation of $o$-orsellinic acid; this was supported by the observation that the introduction of $\left[\mathrm{Me}^{-{ }^{14} \mathrm{C}}\right]$ methionine into the culture fluid of the wild-type led to the indication, by radioautography, of radioactivity in the compound (XIV) but not in the 0 -orsellinic acid.

This is, as far as we are aware, the first case in which 2-hydroxy-6-methylbenzoic acid (X) and $o$-orsellinic acid (XIII) have been found together in the culture fluid of a micro-organism; however, it is to be expected from other evidence (Bentley \& Keil, 1961; Bu'Lock \& Smalley, 1961) that both compounds are derived from a common intermediate formed from malonate and acetate units.

Although this evidence is incomplete, the identification of the simple phenols (X), (XIII) and (XIV) in the early stages of fermentation and in blocked mutants of $A$. terreus does favour the proposal that sulochrin is formed through combination of two phenolic compounds such as 3,5-dihydroxyphthalic acid and $o$-orsellinic acid, or their simple derivatives. The occurrence of sulochrin and related anthraquinones in the culture fluid of $P$. frequentans (Stickings \& Mahmoodian, 1962) may be attributed to a synthesis following a route similar to that proposed by Raistrick (1950). The 3,5-

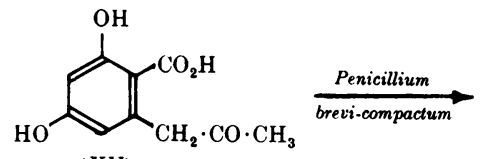
(XV)<smiles>CC1=C2C(=COC(C)C2C)C(O)=C(C(=O)O)C1=O</smiles>

(XVI)<smiles>Cc1cccc(O)c1C(=O)O</smiles>

(X)<smiles>O=C(O)c1cc(O)cc(O)c1C(=O)O</smiles>

(IX) dihydroxyphthalic acid (IX) may be derived either directly from 0 -orsellinic acid, by analogy with the conversion of 2-hydroxy-6-methylbenzoic acid into 3-hydroxyphthalic acid (XVIII) by Penicillium urticae (Tanenbaum \& Bassett, 1958), or through $C$-acetyl-o-orsellinic acid (XV). The latter compound, which has been postulated as an intermediate in the biosynthesis of citrinin, a metabolite of $A$. terreus (Hassall \& Jones, 1962), is the likely precursor of 3,5-dihydroxyphthalic acid (IX) in cultures of Penicillium brevi-compactum (Oxford \& Raistrick, 1932).

\section{SUMMARY}

1. Ultraviolet irradiation of spores of a strain of Aspergillus terreus Thom that produces geodoxin has led to the isolation of new strains with marked differences in their ability to synthesize phenolic compounds.

2. Comparison of the phenolic metabolites of these new strains indicates that processes such as chlorination, oxidation and hydrolysis are under genetic control.

3. The results provide evidence on the stages in the biosynthesis of geodoxin and related compounds.

We are grateful to the Nuffield Foundation for financial support and to the Department of Scientific and Industrial Research for a research studentship (to P. C. H.). We are also grateful to Imperial Chemical Industries Ltd. (Dyestuffs Division), Dr A. I. Scott, Dr C. E. Stickings and Dr C. A. Wachtmeister for supplying reference compounds.

\section{REFERENCES}

Arpai, J. (1959). J. Bact. 78, 153.

Barton, D. H. R. \& Scott, A. I. (1958). J. chem. Soc. p. 1767.

Beijerinck, M. W. (1889). Arch. néerl. Sci. 23, 367.

Bentley, R. \& Keil, J. G. (1961). Proc. chem. Soc., Lond., p. 111.

Bu'Lock, J. \& Smalley, H. M. (1961). Proc. chem. Soc., Lond., p. 209.

Birch, A. J. (1962). Proc. chem. Soc., Lond., p. 3.

Birch, A. J., Fitten, P., Pride, E., Ryan, A. J., Smith, H. \& Whalley, W. B. (1958). J. chem. Soc. p. 4576.

Calam, C. T., Clutterbuck, A. E., Oxford, A. E. \& Raistrick, H. (1947). Biochem. J. 41, 459.

Curtis, R. F., Hassall, C. H. \& Jones, D. W. (1959). Chem. \& Ind. p. 1283.

Curtis, R. F., Hassall, C. H., Jones, D. W. \& Williams, T. W. (1960). J. chem. Soc. p. 4838.

Curtis, R. F., Hassall, C. H., Natori, S. \& Nishikawa, H. (1961). Chem. \& Ind. p. 1360.

Davis, B. D. (1955). Advanc. Enzymol. 16, 247.

Fries, N. (1947). Nature, Lond., 159, 199.

Gatenbeck, S. (1960). Svensk kem. Tidskr. 72, 188.

Geissman, T. A. (1962). The Chemistry of the Flavonoids, p. 598. Oxford: Pergamon Press Ltd.

Giles, N. H., Partridge, C. W. H. \& Nelson, N. J. (1957). Proc. nat. Acad. Sci., Wash., 43, 305. 
Grove, J. F., MacMillan, J., Mulholland, T. P. C. \& Rogers, M. A. T. (1952). J. chem. Soc. p. 3977.

Harborne, J. B. (1960). Biochem. J. 74, 262.

Harborne, J. B. \& Sherratt, H. S. A. (1961). Biochem. J.78, 298.

Hassall, C. H. \& Jones, D. W. (1962). J. chem. Soc. p. 4189.

Hassall, C. H. \& Lewis, J. R. (1961). J. chem. Soc. p. 2312.

Hassall, C. H. \& McMorris, T. C. (1959). J. chem. Soc. p. 2831.

Hoesch, K. (1913). Ber. dtsch. chem. Ges. 46, 886.

Hollaender, A., Raper, K. B. \& Coghill, R. D. (1945). Amer. J. Bot. 32, 160.

Komatsu, E. (1957). Nippon Nogei-Kagaku Kaishi, 31, 905; cited in Chem. Abstr. (1958) 52, 16473.

Miller, M. W. (1961). The Pfizer Handbook of Microbial Metabolites, p. 273. London: McGraw-Hill Book Co. Inc. Nishikawa, H. (1939). Acta phytochim., Tokyo, 11, 167.

Oxford, A. E. \& Raistrick, H. (1932). Biochem. J. 26, 1902.

Raistrick, H. (1950). Acta chem. fenn. 10 A, 221.

Raistrick, H. \& Smith, G. (1936). Biochem. J. 30, 1315.
Reio, L. (1958). J. Chromat. 1, 338.

Rhodes, A., Boothroyd, B., McGonagle, M. P. \& Somerfield, G. A. (1961). Biochem. J. 81, 28.

Rhodes, A., McGonagle, M. P. \& Somerfield, G. A. (1962). Chem. \& Ind. p. 611.

Robertson, A. \& Whalley, W. B. (1949). J. chem. Soc. p. 3038.

Shaw, P. D. \& Hager, L. P. (1961). J. biol. Chem. 236, 1626.

Sinnott, E. W., Dunn, L. C. \& Dobzhansky, T. (1958). Principles of Genetics, 5th ed., p. 225. London: McGrawHill Book Co. Inc.

Stickings, C. E. \& Mahmoodian, A. (1962). Chem. \& Ind. p. 1718.

Strating, J. \& Backer, H. J. (1943). Rec. Trav. chim. PaysBas, 62, 57.

Tanenbaum, S. W. \& Bassett, E. W. (1958). Biochim. biophys. Acta, 28, 21.

Tatum, E. L. (1944). Annu. Rev. Biochem. 13, 667.

Tatum, E. L. \& Bell, T. T. (1946). Amer. J. Bot. 33, 15.

Biochem. J. (1964) 90, 51

\title{
Chemical Studies in Relation to Convulsive Conditions
}

\section{EFFECT OF TELODRIN ON THE LIBERATION AND UTILIZATION OF AMMONIA IN RAT BRAIN}

\author{
By D. E. HATHWAY AND A. MALLINSON \\ Tunstall Laboratory, Shell Research Ltd., Sittingbourne, Kent
}

(Received 7 May 1963)

Acute Telodrin (1,3,4,5,6,7,8,8-octachloro-1,3,$3 a, 4,7,7 a$-hexahydro-4,7-methanoisobenzofuran) intoxication causes an increase in alertness, blood pressure, depth and rate of respiration and in motor activity. Piloerection and decrease in heart rate precede the onset of seizures, during which ptosis and salivation occur; the rat is apparently oblivious of its surroundings. The pharmacological effects of Telodrin relate to the central nervous system and biochemical investigations have therefore been confined to the brain.

In brain, amino acids serve as units for protein synthesis and for the production of amines and enzymes which are important to the metabolism of this organ. The exceptional ability of glutamic acid to undergo oxidation, transamination and decarboxylation, the relatively high concentrations of glutamic acid, glutamine and $\gamma$-aminobutyric acid in the brain as compared with the other organs, and the possibilities of their mutual transformations, emphasize the importance of these compounds in cerebral metabolism. These substances are intimately concerned with the transfer of ammonia in brain. Work on the formation of ammonia in brain slices (Vrba, Folbergr \& Kan- turrek, 1957) and on the perfusion of brain (Geiger, 1958) indicates that the turnover of glutamate and related amino acids is rapid during seizures. This finding, together with the induction of seizures by administration of ammonium salts and the increased formation of cerebral ammonia in seizures, suggest a possible association between convulsions and the metabolism of the glutamate and related amino acids in brain.

Convulsants such as methionine sulphoxime, 3-methyl-3-ethylglutaramide and thiosemicarbazide (Killam, Dasgupta \& Killam, 1960; Tower, 1957) reduce the concentration of $y$-aminobutyric acid and glutamic acid in cortical slices and inhibit glutamine synthesis. Similarly, both human epileptogenic brain and epileptogenic lesions of animal brain produced by freezing cortex with ethyl chloride are unable to maintain the normal concentration of glutamic acid (Berl, Purpura, Gonzalez-Monteagudo \& Waelsch, 1960; Tower, 1960). These observations have therefore prompted the present investigation of possible disturbances in the cerebral amino acids and related substances which may be associated with Telodrin-induced behavioural changes. 